\title{
Global Supply-Chain Strategy And Global Competitiveness
}

Asghar Sabbaghi, (E-mail: sabbaghi@iusb.edu), Indiana University South Bend Navid Sabbaghi, Massachusetts Institute of Technology

\begin{abstract}
The purpose of this study is to provide an analysis of global supply chain in a broader context that encompasses not only the producing company, but suppliers and customers. The theme of this study is to identify global sourcing and selling options, to enhance customer service and value added, to optimize inventory performance, to reduce total delivered costs and lead times, to achieve lower break-even costs, and to improve operational flexibility, customization and partner relations. In this context, an integrated management information system will be viewed as the key instrument that captures all relevant data and makes it available to the appropriate decision-maker and that provides an optimizer and decision-support function supporting various phases of the decision-making process, requiring the identification of cost cutting and value adding strategies. The properly integrated management information systems will help companies to gain the critical global competitive edge to survive in today's markets. We suggest various strategies in sourcing, manufacturing/operation, and marketing that can provide a competitive global supply chain strategy for a firm to increase value. We provide case studies where these strategies have been successful as well as case studies where they have failed.
\end{abstract}

\section{Introduction}

Advances in information technology, introduction of new products with shorter life cycles, intensified competition in today's global markets, and the heightened expectations of customers have contributed to the development of new approaches to supply chain management. Traditionally, raw materials are procured and items are produced at one or more factories, shipped to warehouses for immediate storage, and then shipped to retailers or customers. Therefore, in order to reduce costs and improve service levels, effective supply chain strategies must take the interactions at various levels of the supply chain into consideration. In recent years, the pressure to find consumer-responsive and cost efficient solution to supply chain issues in a market place has forced closer collaboration between retailers and manufacturers in order to combat the challenges that result from asymmetric information and the bullwhip effect.

Many firms can no longer afford to have their supply chain located in a single country. If they do, they run the risk of becoming less competitive and delivering less value than they are capable of delivering. The main reason is that the location at which a firm chooses to source its raw materials, to hire its labor, to locate its manufacturing/operation facilities, and to serve demand can greatly influence a firm's cost-benefit measures and its investment decisions. While designing an effective global supply chain is a challenge, it can be a rewarding one because it can create more valuable products/services that a firm delivers.

This growing concern has created an incentive for more effective and efficient design of supply chains and of management in utilizing consumer response. In a global market, supply chain management is more complex since suppliers and partners are located in different countries and the classical logistics of facility location, sourcing, and distribution are greatly influenced by political and economic factors. Varying tax and customs rules, production/operation expenses, multiple currencies and numerous transportation problems are among the challenges of linking a transnational supply chain. However, we will see that this flexibility also enhances our supply chain design capability. 
In this study, we suggest various strategies in sourcing, manufacturing/operation, and marketing and distribution that can provide a competitive global supply chain strategy in order for a firm to increase the value of its products/services to the end customer. We provide case studies where these strategies have been successful as well as case studies where they have failed. We also develop a framework for understanding and contrasting the impact of consumer response at various stages of the supply chain.

\section{Conceptual Framework: Supply Chain Integration}

Forrester (1958) viewed a supply chain as part of an industrial dynamics, alternatively known as system dynamics and management system dynamics; it is broadly defined as the application of feedback thinking and control engineering concepts to the study of economic, business and organizational systems. System dynamics is concerned with problem solving in living systems which bring together machines, people and organizations. It links together the system theory and the control theory so that we are able to generate added insight into system dynamic behavior and particularly, into the underlying causal relationships in the context of global performance of the system and internal control. In this context, supply chain is defined as a system of business enterprises that link together to satisfy customer demands and to provide value to the end customer in terms of product and services. We can discern a distinct generic procedure as part of the production/operation process in supply chain that is called an echelon. In their most basic form, materials/goods flow from one echelon to the next until they reach the end customer. In reality, however, supply chains do not exist in isolation, but form part of a network of supply chains satisfying different demands.

Prior to the supply chain era, it was assumed that each echelon in the supply chain would operate independently. Managers at each stage made decisions based on the requirements and objectives of the particular activity with only cursory attention to the constraints imposed by neighboring echelons. As a result, each echelon attempted to optimize its own operation in isolation. A sequence of locally optimized systems does not necessarily constitute a global optimum.

Supply chain integration and aligned decisions to accomplish global system objectives depend on the quality of information/knowledge flows between echelons. The information/knowledge flow has become an extremely important factor for success in supply chain management. Traditionally, information is viewed as flowing in the opposite direction of product/material from market/customer, which filtered back to the wholesaler, manufacturer, and vendors. The information was primarily demand or sale data, which were the triggers for replenishment and the basis for forecasting. However, figure (1) indicates a two-way flow of information/knowledge. In a supply chain environment, information flowing forward in the supply chain has taken an increased significance and importance. Forward information/knowledge flow may range from tactical/operational information such as advanced shipment notice, order status, and inventory availability to strategic information/knowledge about the suppliers and opportunities for partnership. The information/knowledge flow provides the opportunity to improve the way supply chain is designed and managed. It helps to reduce variability in the supply chain and helps suppliers make better forecasts, because it accounts for promotion and changes. It also enables the coordination of manufacturing and distribution systems and strategies, enables retailers to better serve their customers by offering tools for locating desired items, allows them to react and adapt to supply problems more rapidly, and helps to reduce lead time. 
Figure 1: Global Supply Chain Management and the Value Chain

\section{Competitive Advantage \\ strategies}

Integrating management of Business Processes Across the supply chain Production/Operation Flow

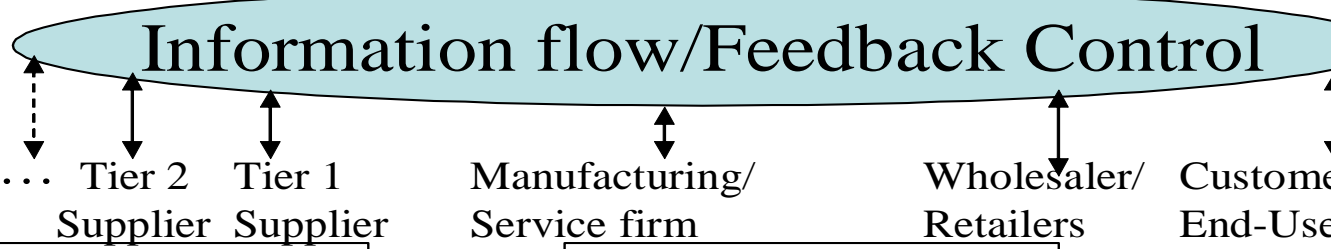

Product Differentiation

Supplier Knowledge Service firm Retailers End-Use

Cost Leadership Customer Expectation New Product

Development Profitability Speed to Market

Integrated Value Chain (Profit

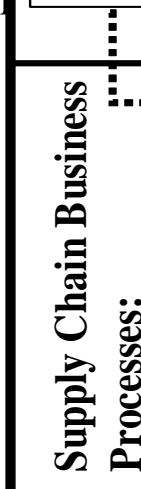
Collaboration on Supply requirements Service Knowledge Collaboratio ; and/or CustomerCustomer Relationship Management Customer Service Management Demand management Order Fulfillment

$\because$ Manufacturing Flow management Supplier Relationship Management Product Development and Commercialization Returns Management

Perceived Value)

Information Technology Management: Collaborative eCommerce and Supply Chain Intelligence

\section{Back-End Supply Chain}

Integrated Approach:

Partnership Strategy Tactical Management Strategic management 
Lack of coordination occurs when decision makers have incomplete information/intelligence about the production/service, process, or market conditions, or there are incentives for various parties that are not compatible with system-wide objectives. Even under conditions of full information availability, the performance of the supply chain can be sub-optimal when each decision maker optimizes his/her individual objective function. There has to be a systemic incentive for full information/intelligence sharing to support the specific decision-making environment throughout supply the chain. This could include production/operation status and cost, transportation/distribution availability and quantity discounts, inventory levels and cost, various capacities, demand data from all channel members, and planned promotion strategies. Anand and Mendelson (1997) studied the impact of coordination structures, namely information structure and decision authority, on firm performance. In their view, information structure consists of two components: (a) knowledge that cannot be transferred among market areas, and (b) data that can be transferred. The decision authority is classified as either decentralized or centralized decision-making. Then, they consider four coordination structures: (1) centralized, that center makes all the decisions using all the data but none of the local knowledge; (2) decentralized, each market makes its own decisions using its local knowledge and data; (3) fully distributed, all data is shared and hence, each branch makes its decision based on both its own local knowledge and all system data: and (4) no information, only local knowledge is used in a decentralized decision environment. Chen (1998) studies the value of centralized demand information in a serial inventory system of $\mathrm{N}$ stages with random customer demand at the last stage. His study, while limited to the single item assumption, provides numerical evidence on the value of information sharing and physical flow coordination in multi-stage supply chain.

Figure (1) shows a relatively simple and generic supply chain that links a company with its suppliers, upstream (on the left), and its distributors and customers, downstream (on the right). Upstream supply chain includes the organization's first tier suppliers (which themselves can be manufacturers and/or assemblers) and their suppliers. Such a relationship can be extended to the left, in several tiers, all the way to the origin of material. Downstream supply chain includes all the processes involved in delivering the product/service to the final customers. It will actually end when the product reaches its final consumer. Thus, there are physical flows in the form of raw materials, work-in-process inventories, and finished products/services, between supply chain echelons, from suppliers/vendors (upstream) to manufacturers, to distributors and retailers, and to final consumers (downstream). Supply chain also includes the movement of information and money, and the procedures that support the movement of a product/service. Managing these physical and informational flows effectively and efficiently requires an integration approach that promotes organizational relationships and fosters the sharing of strategic and technological efforts.

Figure (1) also shows supply chain strategies to gain competitive advantage within Porter's model (1996), namely establishing a profitable and sustainable position in the marketplace through cost leadership, product/service differentiation, and customer expectation. Value chain is viewed as another important tool to dissect the key components of value as a way to understand competitive advantage in an industry. The value chain is composed of all of the components of value associated with activities used to produce a product/service and the importance of each activity. In particular, various strategies are evaluated by the value added to each product/service in the supply chain process. For instance, the incoming materials are processed in receiving, storage, etc, and in this processing, value is added to them. Similarly, materials are used in operation where more value is added in providing the products/services. The products/services need to be prepared for delivery (packaging, storing, and shipping) and so more value is added. An attempt is made to sell the products to customers, increasing product value by creating demand for the company's product/service. Finally, after-sale service is offered to customers, further adding value. As shown in figure (1), we consider a firm's value chain in a broader context so that it would include the suppliers/vendors that provide the inputs necessary to the firm and their value chain as well as the upstream echelons and their value chains. Gaining and sustaining a competitive advantage, and supporting that advantage by supply chain strategies require an understanding of this entire value chain.

The value-added in the chain comprises two elements: (1) the financial component, evaluated by a quantitative model, utilizing traditional economic value added (EVA) analysis, and (2) the strategic component, evaluated by a qualitative model, representing the decision model supporting supply chain strategies. For example, when considering procurement strategies, one may apply a quantitative model by focusing on two financial streams: 
income and capital costs. Thus, whether sourcing is viewed as a cost center or a revenue center, maximization of net operating profit after tax or minimization of cost, it may be defined as an objective of the decision. Similarly, the capital cost and the type of return on capital generated, in relation to an industry benchmark, can determine the sourcing decision based on the quantitative model. On the other hand, strategic components of procurement decisions, according to Fine et al (2001), may include the following components: (a) customer importance (how does a sourcing decision affect customer preferences), (b) technology lifecycle (how rapidly is the underlying technology changing), (c) competitive position (how does the firm stack up to its competition in achieving cost, quality, technology, etc), (d) supply base capability (how deep and capable is the outside supply base for outsourcing), and (e) architectural relationship (how integral or modular is this value chain element to the overall product, service, or system of which it is a component).

Fine (1998) uses the concept of "clockspeed" to describe the technology lifecycle and the rates at which companies and industries evolve. Industry clockspeed, in his view, is measured by the rates of change in product development, process creation, and organization renewal. He cites the information-technology industry as composed of many fast-clockspeed firms - what he calls the industrial fruit flies. On the other hand, heavy manufacturing and mining companies exhibit much slower clockspeeds - he calls them the dinosaurs. He noted that there are two factors that affect industry clockspeed: (a) technological innovation, and (b) competition intensity. As a new technology emerges, the industry clockspeed increases, and as the faster the industry clockspeed, the more important the supply value chain design. He cited optical communication industry as the fastest clockspeed and the competitive advantage is established by the technology edge. Strategic supply chain design is based on the competence of the firm because individual capability can lose value overnight by new or rapidly evolving technologies or by the new tactics of competitors. This is particularly the case for optical components, because the competitive advantage in optical industry is established by the technological edge, which is temporary, and the switching cost is minimal. A radical technology innovation can enter the market quickly and threatens the existing suppliers.

Ulrich (1995) describes the concept of product architecture, and distinguishes between integral and modular product architectures. According to this definition, a product with a modular architecture has components that can be mixed and matched due to standardization of function and interface. In this context, home stereo equipment has a modular architecture; one can choose speakers from one company, a CD player from another, a tape deck from third, etc, and all the parts from the different manufacturers will assembled together into a system. On the other hand, a product with integral architecture is not made up of off-the-shelf parts, but rather comprises a set of components and subsystems designed to fit with each other. Functions are typically shared by components, and components often display multiple functions. The product in this case must be developed as a system and the components and subsystems defined by a design process exerted from the top down, rather than the bottom-up design process.

In the context of value chain strategy, an organization faces a complex array of challenging issues such as: Where is value being created and what activities are not adding to overall enterprise value? What areas of the business should remain in-house versus being outsourced? Where should the organization make investments? How can these be leveraged? How can the organization optimize its value chain to govern its destiny with mutual benefit among existing and emerging alliance partners?

For example, the procurement decision, in-sourcing versus outsourcing, is becoming more important if the source of supply makes a significant difference to the customer. In the personal computer industry, during the 1980 's, it was the original equipment manufacturers such as IBM or Apple that were important to customers. However, today, the customers care far more about the supplier's logo-"Intel Inside" or Windows 2000", than about the brand name of the company that assembled the components and ship the final product.

As Fine (1998) notes, when designing a supply chain, make vs. buy decision should not be made primarily on which supply option is a little less expensive or a little bit faster to market. Rather, it should be recognized as a strategic activity that can determine the fates of companies and industries as well as of profits and power. In general, outsourcing can provide a way to access necessary resources and capabilities more quickly. A 
company can often access and mobilize the resources of its suppliers without investing in a lot of its own fixed assets. Outsourcing will also provide flexibility if the market conditions change so that firms can access new set of resources and capabilities. When it is unwieldy to forecast exactly what resources and capabilities are needed, outsourcing can be a way to hedge bets and adapt more readily to changing market conditions. There may also be flexibility in terms of creating a more variable cost structure that can dampen the impact of revenue downturn. On the other hand, when the lifecycle of the technology for a component is fast, it would be risky to be fully dependent on outsourcing. In-sourcing will be more desirable for companies with stronger competitive position in designing or making the value chain element. It is safer to outsource when there is a more capable supply base (number of viable suppliers and their technological competency). Finally, following Fine and Whitney (1996), when there is an integral architecture that exhibits close coupling among the elements of the product, it is risky to be fully dependent on an outside supplier. On the other end of spectrum, modular architecture features decoupling among a system's components and make it less risky for outsourcing a component.

In recent years, there has been a shift of focus in supply chain management toward a more integrated approach to procuring, producing, and distributing products and services to customers. In this context, we envision the supply chain management to include further the source of supply and downstream to the point of consumption (Lambert et al 1998), and adopt eight key processes identified by the global supply chain forum that make up the core of this modified definition of supply chain management by Croxton et al (2001) as follows:

Customer Relationship Management: Provides structure for how the customer relations are developed and maintained. Identifies target customer groups as part of the business mission and develops agreements with key accounts. Performance reports also measure profitability and financial impact for key customers.

Customer Service Management: Provides the source of customer information such as ship dates, product availability, and real-time information between customers and the firm.

Demand Management: Balances the customers' requirements with the firm's supply capabilities. This would include forecasting demand and timing it with production, procurement, and distribution and basically all demands of output of the company.

Order Fulfillment Management: Provides integration of the firm's manufacturing, logistics and marketing plans. This would require the management of partnerships maintained by the company to meet customer requirements.

Manufacturing Flow Management: Produces the products and establishes the manufacturing flexibility required to service target markets. Requires management of product flow and maintaining the flexibility established.

Supplier Relationship Management: Defines how a company interacts with its suppliers. Similar to customer relationship management, partnership management is required to develop key relationships with core suppliers, potentially providing a competitive advantage.

Product Development and Commercialization: Provides the development of new products by integrating customers and suppliers in order to reduce time to market. Timely development of new products and services are keys to a firm's success.

Returns Management: Provides a critical component of sustained competitive advantage for the firm. Allows firm to monitor productivity improvements and identify valuable projects related to products or services.

These processes provide a framework for various aspects of strategic and tactical issues present in the management of the supply chain.

According to Hammer (2001), companies need to integrate the processes between the firms and to streamline cross-company processes for reducing costs, enhancing quality, and speeding up operations. In order to survive, they need to take a new approach to business by working closely with partners.

At any point in time, each supply chain entity can have both multiple suppliers and multiple customers.

A combination of economic, technological, and market forces has compelled companies to examine and redesign their supply chain strategies. In order to stay competitive in the market place, companies have strived to achieve greater cooperation and collaboration among supply chain partners in an approach called virtual integration of supply chain. Virtual integration, in contrast to the more traditional vertical integration, can be viewed as the 
selection, partnering, and integration of key intellectual capital across the supply chain, and to gain synergy of resources in creating value for end-use customer. This model involves not necessarily outsourcing supply chain capabilities, but simply making the right choice about which processes to retain in house and which to outsource. It defines the framework for partnering and aligning one's business with others that differentiate themselves by performance and continue to make capital asset investment in processes, technology, and intellectual capital. In this model, the ability to develop effective collaborations will play a key role to success. In particular, since many supply chain innovations are multi-organizational by definition, the knowledge and skill sets relating to the formation, sustainability, and evolution of collaborative relationships are essential capabilities. The challenge in integrating and redesigning an effective and efficient supply chain is the difficulty in adopting a strategy that helps enterprises to improve performance simultaneously across many different metrics: reducing cost, increasing service level, optimizing the utilization of resources, and effectively responding to changes in the market place. These goals cannot be achieved simply by coordinating production, distribution, and inventory decisions, but these challenges require an integration of the front-end of the supply chain, customer demand, to the back-end of the supply chain, the procurement of supplies and the supply chain's manufacturing processes. In particular, appropriate IT strategy can play an instrumental role in this integration effort and can significantly add value to this process. Cisco, for example, has pioneered a network of partnership, called "internet ecosystem", across its supply chain. In its network, the company connects chip manufactures, component distributors, contract manufacturers, logistic companies, employees, system integrators, and customers. These business web participants can perform like one firm because they all draw upon the same well of information. Cisco's core products-networking devices and software are more or less mass produced. While it is known as a manufacturer, Cisco owns only two of the 38 plants that assemble its products. It delegates nearly all the complicated manufacturing, assembling, product configuration, and distribution activities to partners. While it does not control or micromanage, it shares responsibility for customer satisfaction. Thus, a group of highly specialized companies, through process networks, are mobilized to support core business processes, typically supply chain management, customer relationship management, or collaborative product development. According to Michael Dell, reported by Margretta (1998), "Virtual integration harnesses the economic benefits of very different models. It offers the advantages of a tightly coordinated supply chain that has traditionally come through vertical coordination. At the same time, it benefits from the focus and specialization that drives virtual corporations. Virtual integration has the potential to achieve both coordination and focus. If it delivers on that promise, it may well become a new organizational model for the information age."

\section{Supply Chain Dynamics and Bullwhip Effect}

Application of system dynamics (Forrester 1958 and 1961) concepts in supply chain provides insight and knowledge that would help one to evaluate business performance against competition, using typical criteria such as speed of new products to market and the rate of turning around our stocks yet simultaneously satisfy customer demand. According to Forrester (1961), "systems of information feedback control are fundamental to all life and human endeavor, from the slow pace of biological evolution to the launching of the latest satellite. A feedback control system exists whenever the environment causes a decision which in turn affects the original environment. ... In business, orders and inventory levels lead to manufacturing decisions, which fill orders and correct inventories. A profitable industry attracts competitors until, using economics' term; the profit margin is reduced to equilibrium with other economic forces. The competitive need for a new product leads to research and development expenditure that produces technological change. ... Feedback theory explains how decisions, delays and predictions can produce either good control or dramatically unstable operation."

Theory of Industrial Dynamics can be used to anchor our current understanding of supply chain coordination and management. A key component of this theory rests on understanding the dynamics of how the delays, amplifications, and oscillation in the flow of demand information aversely affect supply chain operation, most noticeably inventory levels and production rates. According to Forrester (1961), management is on the verge of a major breakthrough in understanding how industrial company success depends on the interaction between flow of information, materials, money, manpower, and capital equipment. The way these five flow systems interlock to amplify one another and to cause changes form a basis for anticipating the effects of decisions, policies, organizational forms, and investment choices. Only through this understanding and continued development of the 
"tools of progress" such as today's advances in information technologies, can new management concepts be implemented.

For instance, there is a downstream flow of material from the factory via factory warehouse, the distributor and the retailer to the customer. Orders (information flow) flow upstream and there is a delay associated with each echelon in the chain, representing the production lead-time or delays for administrative tasks such as order processing. Companies then use inventories not only to hedge against demand changes, but also against capacity changes and this would lead to amplified demand at each echelon toward upstream. Thus, according to supply chain dynamics, the magnitude of demand volatility a company faces increases the further upstream it resides in the supply chain, For example, personal computer manufacturers experience less demand volatility than semiconductor manufacturers, who, in turn, experience less demand volatility than their semiconductor equipment suppliers. This phenomenon known as "Forrester " or "bullwhip effect" refers to the similarity between the graphical behavior of demand and the cracking of a whip. This effect is apparent in the operations of traditional industry echelons. First, the supplier receives a replenishment order that includes sufficient quantity to restock the actual units sold, plus any adjustments to safety stock and pipeline inventory necessary to compensate for a possible shift in the demand pattern. These adjustments, which are passed to the distributor in the form of an overstated order, amplify the distributor's perception of system demand. Replication of this process at each stage of the supply chain amplifies the information distortion, causing all channel members upstream of the retailer to lose track of the actual customer demand pattern so that system-wide inventory control suffers. Potential causes of demand amplification are seasonal retail sales variations, uncertainty in the quality of information passed between echelons, poor demand forecasting either unintentional or caused by tendentious "forecasts" by ambitious sales departments, random fluctuations in sales, advertising and price discount policies, factory capacity limitations that encourage over-ordering in times of shortages, order cycle lead-time that delays transmittal of timely demand information, and additional purchasing and inventory policies that over-react to perceived changes in the demand pattern. According to Forrester (1961), strategies may include shortening the order cycle lead-time, sharing retailers' point of sales data with all channel members, and alter inventory control procedures to provide a more gradual correction to demand change.

Thus, upstream behavior is triggered by downstream decision-making but in such a way that the companies involved respond blindly to the real world. False seasonal demands are induced by random market sales operating on the system dynamics, which is extremely confusing for all upstream resource planners and decision makers. Furthermore, the time for the wave form to move upstream is beyond the comprehension of most managers.

\section{Supply Chain Strategies}

Traditionally, in the market economy, products and services are produced to meet the forecasted demand. The optimum competitive decision is often accepted as achieving economies of scale and/or economies of scope. Productive processes are arranged so as to optimize the utilization of production and distribution capacity. In this economy, sharing technology and expertise with customers or suppliers was considered risky and thus unacceptable. There has been much emphasis on in-sourcing and vertical integration in supply chain strategies and little emphasis on outsourcing and cooperative and strategic buyer-supplier partnership. For example, in the computer industry, companies such as IBM or Digital Equipment Corporation tended to provide most of the key elements of their own computer systems, from operating system and application software to the peripherals and electronic hardware, rather than sourcing bundles of subsystem modules acquired from third parties. Products and computer systems typically exhibited closed, integral architectures; there was little or no interchangeability across different companies' systems, and this kept existing customers hostage. Each company maintained technological competencies across many elements in the chain, and emphasized the value of its overall systems-and-service package, determined to stave off competitors who might offer better performance on one or another piece of the package. Thus, the supply chain strategy in the market economy has been designed to "push" products to the customer based on forecasted demand. It focuses on supporting a tightly integrated enterprise geared toward mass production of goods at the lowest possible price. The production processes across the supply chain are synchronized for efficient utilization of all resources. Information technology, however, acts as an enabler for operational optimization across the supply chain by offering customer driven forecasts in addition to robustly synchronizing the sourcing, production, and processes across the supply chain in order to achieve optimal performance, even if the forecasts are not perfect. For example, 
in car manufacturing, cars are traditionally manufactured to match forecasted demand that lacks much customer input.

However, in the new information economy, also called the internet economy or the web economy, information technologies, digital networking and communication infrastructures provide a global platform over which people and organizations interact, communicate, collaborate, and search for information. The internet has created more sophisticated customers who demand innovative, personalized products/services delivered at their convenience. It has also expanded the very definition of the word "customer", so that it now includes employees, distributors, suppliers, business partners, and shareholders. As a result of these changes, a company's competitive position in this internet economy depends on its ability to deliver customized, relevant, highly responsive service to every participant in these networks of economic relationships. This new economy has led to the rapid emergence of business networks and new business models within and outside the firm to satisfy the strategic need for competitive flexibility. In this new economy, the supply chain is geared toward the customer "pulling" products customized to their specific needs, and the firm's resources are organized to meet the unpredictable demand patterns of the customer. Furthermore, companies attempt to improve their sales by pulling their product through the distribution channel with promotional advertising, and to create or stimulate sales to customers. Therefore, the benefits of supply chain management integration promote organizational relationships that in turn foster the sharing of information technology and strategic efforts.

Selen and Soliman (2002) have proposed demand chain management (DCM) to reflect the new role for SCM concept and have argued that the shift in power from the supplier to customer should lead to analyzing supply chains from a demand perspective. One may relate this to the tactical/operational distinction between material requirement planning (MRP) and Just-In-Time (JIT) systems. In the market economy, most manufacturers emphasized mass production to minimize unit production cost as the primary operation strategy, with little product or process flexibility. Thus, new product development was slow and relied exclusively on in-house technology and capacity. Excess inventory was used to cushion bottleneck operations to maintain a balanced line flow, thus resulting in huge investments in work-in-process (WIP) inventory. MRP was developed and managers realized the impact of significant WIP inventories on manufacturing cost, quality, product development, and delivery lead-time. On the other hand, the intense global competition of the 1980s forced world-class organizations to offer low-cost, high-quality, and reliable products with greater design flexibility. JIT and other management programs were utilized to improve manufacturing efficiency and cycle time. In the fast-paced JIT manufacturing environment with little inventory to cushion production problems, manufacturers began to realize the potential benefits and importance of strategic and cooperative buyer-supplier relationships. In this process the concept of SCM has emerged as manufacturers experimented with strategic partnership with immediate suppliers. In addition, to procurement professionals, logistic experts carried the concept a step further to incorporate the physical distribution, transmission, and warehousing function (Tan 2001). It is often argued that MRP was a "push" system based on forecasted demand while JIT was a "pull" system based on actual demand. However, we consider SCM and DCM interchangeably and apply push and pull concepts to analyze various strategies. For example, it is argued that for mature products with slower clockspeed, it may be more effective to use push approach, since it is easier to generate accurate demand forecasts. On the other hand, for faster clockspeed products such as electronics and retail products, it would be difficult to generate accurate demand forecasts and thus pull system would be more effective.

Historically, many camps compared and contrasted these two supply chain strategies: push-based and pullbased, and have favored either a full pull-based strategy or a full push-based strategy. However, there are advantages and disadvantages to both these strategic models. This duality has led companies to look for new hybrid supply chain strategies that take advantage of the strengths of both pull-based and push-based strategies. In our study, we will examine how to combine these strategies for various types of products or industries in order to maximize value. In particular, one may observe that a global market provides us with sufficient design flexibility in order to maximize value for a fixed hybrid strategy. More specifically, imagine the supply chain from the back-end, initial sourcing of inputs to manufacturing, distribution, to wholesaler, to retailer, and to the end customer. In the earlier processes of a supply chain, which includes raw material procurement, a push strategy may prove to be more effective. However, as the product moves toward downstream and approaches the front-end in supply chain, the pull model may play a more effective role for an optimum supply chain strategy. 
Figure 2: Supply Chain Time Line

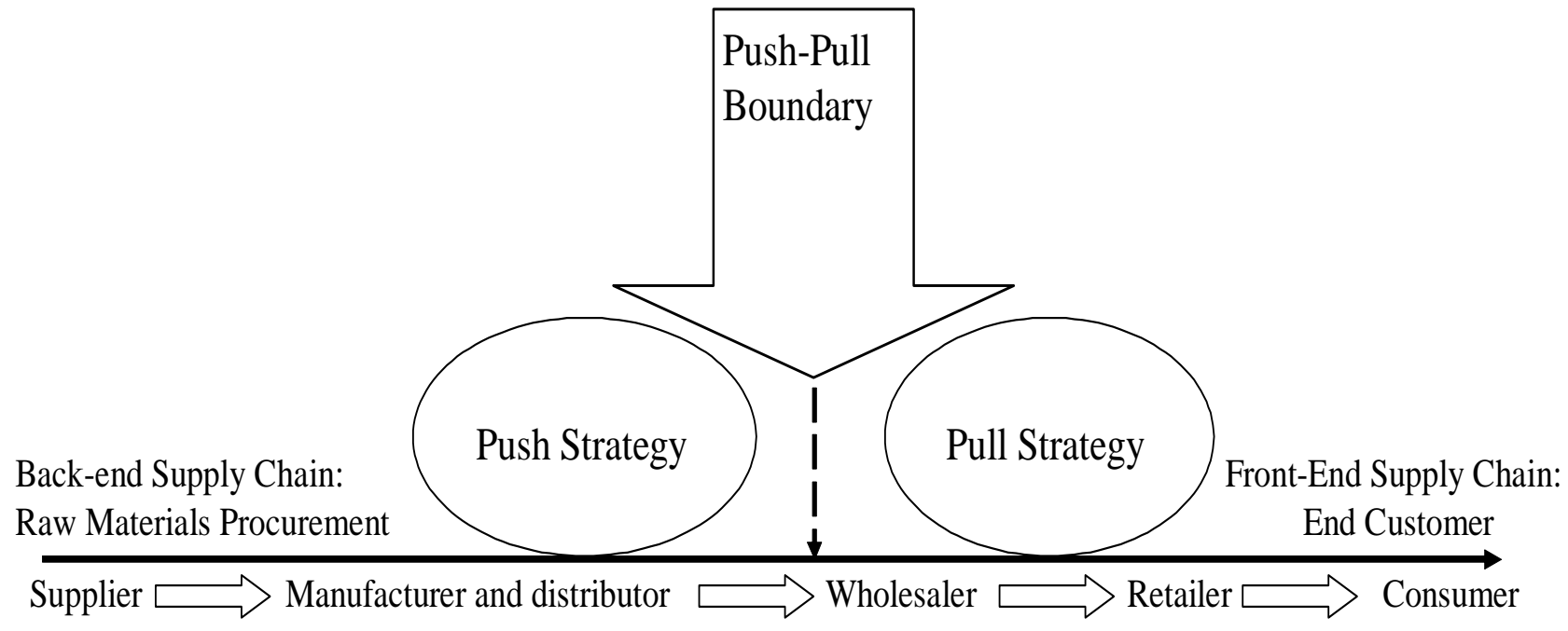

Simchi-Levi, Kaminsky, and Simchi-Levi (2003) have provided a framework matching supply chain strategies with products and industries and have argued that uncertainty of customer demand and the importance of economies of scale will determine the type of supply chain strategy for any specific product or industry. According to this framework, while higher demand uncertainty would lead to a preference for managing the supply chain based on realized demand, a pull strategy, smaller demand uncertainty would lead to an interest in managing the supply chain based on a long-term forecast, a push strategy. Similarly, the greater the importance of economies of scale in reducing the cost, the greater the value of aggregating demand, and thus the greater the importance of managing the supply chain based on a long-term forecast, a push-based strategy. If economies of scale are not important, aggregation does not reduce the cost and therefore, a pull-based strategy would be more effective. In this twodimensional framework, one can define four area industries or products requiring specific supply chain strategies. One area is characterized by high demand uncertainty while economies of scale in production, assembly, and/or in distribution are not of primary importance. According to this framework, in such an industry, pull-based supply chain would be appropriate. The second area would represent an industry or product that would have high uncertainty in demand; however, economies of scale are important in reducing production and/or delivery costs. In this case, one needs to distinguish between the production and the distribution strategies. The production decisions have to follow a pull-based strategy, however, the distribution decisions need to take advantage of economies of scale in order to reduce transportation costs. The third area is characterized by low demand uncertainty and pivotal use of economies of scale. In this situation the traditional push model would be appropriate since managing inventory based on long-term forecasts does not increase inventory holding costs while delivery costs are reduced by leveraging economies of scale. The fourth area represents products and industries that may be characterized by low demand uncertainty, indicating a push-based supply chain, and marginal use of economies of scale, suggesting a pull-based supply chain strategy. The effectiveness of these various strategies depends on the values added in the supply chain process.

\section{Global Supply Chain and Partnership Strategies}

Global supply chains are becoming increasingly significant as they provide a wealth of additional opportunities created by foreign customers and suppliers, as well as pressures created by foreign competitors. As it is often said, even if companies don't do business internationally, the presence of foreign competitors in home markets can affect their business significantly. Therefore, the management of these potential opportunities and threats by any company are critically important for successful business. We consider global supply chain in a more generic sense where a company has the option to globalize a subset or the entire set of its supply chain processes. A company may source raw materials and components from global suppliers, but final assembly may be performed 
domestically. We distinguish global company from one whose operations are simply multi-domestic and tend to operate within individual markets throughout the world, but do not emphasize coordinating individual strategies into a cohesive global strategy. Global companies formulate pull strategy on a worldwide basis to exploit new market opportunities, seek to influence their industries' competitive balance, and implement global strategy effectively and efficiently. Canon, for example, in marketing its new $35 \mathrm{~mm}$ automatic camera, decided to create a single "world camera" that responded to the collective preference of wide variety of potential purchases. However, to customize its appeal to buyers in individual countries, Cannon positioned the camera differently in various market areas. While in the US cannon was described as "easy to use", thus appealing to the growing market of non-professional photographers who nevertheless wanted a product of reasonable quality. However, in Japan, it was presented as the state-of-the-art, considering many Japanese buyers' strong desire for the latest and most advanced electronic equipment. Finally, in a fully global supply chain, products are supplied, manufactured, and distributed from various facilities located throughout the world. For companies like global sports apparel giant Nike, for example, it makes sense to manufacture goods in one place -- like Southeast Asia -- and ship the goods around the world. The global brand is viewed as part of Nike's value proposition. To meet the demands, the company implemented a global trade management application in order to coordinate relationships and financial settlement processes with suppliers around the world. One can contrast Nike's type of enterprise -- a truly global company -- with multinational firms, whose supply chains cross only a limited number of international borders. On the other hand, a cement manufacturer, though international, would not encounter nearly the same level of international supply chain complexity as one that ships goods around the world.

Lucent Technologies, a by-product of the 1984 split of AT\&T, had a flagship product, the 5ESS Switch, which was the world's most reliable and widely used switching system. The switch was composed of an Administrative Module (AM), a Communication Module (CM), and one or more Switching modules (SM). Each switch was comprised of more than 3000 components, some made from generally available parts, others from Lucent proprietary parts. Each customer had specific needs and the switch was custom configured for each order, with only a few assemblies built to stock. In addition to the US market, Lucent established four Asian joint ventures to introduce its flagship product into the Asian telecommunication market with the support of the Asian governments. They included Taiwan (1985), Indonesia (1991), China (1993), and India (1993). The Taiwan Joint ventures, for example, were $85 \%$ owned by Lucent. While Asia was becoming an important segment of Lucent's business and there was tremendous potential for future growth, however, two competitive issues were challenging: cost and delivery time. Their supply chain was not cost effective and delivery time was too long. Asia had been supplied exclusively from the Oklahoma City manufacturing plant. However, about $90 \%$ of the parts were made in Asia, shipped to the United States to be assembled, and then shipped back to Asia. Another factor that contributed to Lucent's financial challenges was Lucent's independence from AT\&T in 1996; they no longer had the service revenue of over $\$ 40$ billion to help cover up the lack of efficiency in delivering their product to their customers. Burgeoning telecommunication providers needed equipment fast in order to not lose customers to the other new companies that starting forming after deregulation.

\section{Global Sourcing}

Sourcing units traditionally focus on finding suppliers that can provide raw materials at low cost with small lead times and high quality. They then develop exclusive relationships and partnerships with a select group of competitive suppliers. The search for lower cost suppliers has been greatly aided by the expansion of supply chains to other parts of the world. These suppliers often have better cost structures usually due to the decreased cost of labor in other parts of the world.

Also, the location of a supplier can often be an important factor since, for some goods, transportation can be a major fraction of the lead-time and cost. So in those circumstances it may be better to locate closer to the supplier. However, simply locating a manufacturing plant closer to a supplier is an example of local optimization. Transportation cost should be viewed as subset of the entire supply chain in which the cost of plant operation is part of the equation. 
Reverse auctions are an e-business tool that allows the supplier to bid for jobs. This has the potential of revealing least cost suppliers that have streamlined their process. However at the same time, it also reveals those suppliers that settle for miniscule margins. These latter suppliers actually may not be healthy suppliers to work with, in that they settle for margins that could put them out of business years down the line. In this way, reverse auctions are not always the best way to single out suppliers to work with. One of the critical challenges in procurement is the selection of strategic partners that will furnish the necessary products, components, and materials in a timely and effective manner to help maintain a competitive advantage. Buyer-supplier relationships based solely on price are no longer acceptable for suppliers of critical materials or for organizations that wish to practice the latest innovations in supply chain management. There has been an emphasis on other important strategic and operational factors such as quality, delivery, and flexibility. Strategic relationships also play a vital role for long-term well-being of a supply chain. Saaty (1996) proposed an Analytical Network Process (ANP) model that incorporates a number of factors in strategic supplier selection. These factors include emphasis on quality at the source, design competency; process capability; declining work-in-process (WIP), lead-time, space, flow distance; operators' ability to present Statistical Process Control (SPC) and quick set up among others. These factors are divided into two groups, namely strategic performance metrics and flexibility. The first group, strategic performance metrics, focuses on four major metrics including cost, quality, time and flexibility. The second group, organizational factors, contains three sets of factors: culture, technology, and relationships. These factors focus less on the competitive factors associated with operational measures and more on the capabilities and characteristics of the organizations that will form the partnership. A utility function or desirability index is utilized to evaluate suppliers and to determine the preference of supplier selection. In particular, companies have increasingly adopted global procurement strategies in support of their global business strategy and they are viewed as critical to realizing competitive advantage. On the other hand, many companies continue to struggle with global procurement and need to have a better understanding of the requirements for effective global sourcing strategies. Global sourcing requires the integration and coordination of procurement requirements across worldwide business units, and the examination and creation of common items, processes technologies, and suppliers (Monczka and tent 1991). Peterson et al (2000) have identified three primary strategies for global sourcing: (1) finding qualified suppliers for the required materials and services; (2) entering into joint-venture relationships; and (3) making a 100 percent equity investment in a foreign country. These strategies progressively require more capital and longer-term commitments. In this regard, Deere Co., a company with a global supply chain, has an interesting program where it assembles a 100-person group in its sourcing team that visits the suppliers it creates relationships with and offers their consulting services to streamline the business processes of its partners, improving their cost structure, and their margins at the same time, in order to guarantee a healthy supply partner for the future. It is rare for a company to take the time to make sure their suppliers are faring well in their business. But in hindsight, if their suppliers are doing well, it feeds back and ensures a solid foundation for the success of Deere Co.

\section{Global Manufacturing}

A manufacturing plant often wants to reduce lead time for its products and to do so with the least cost in terms of inventory cost and process cost. Lead time, in turn, is composed of four parts: setup time, process time, queue time, and move time. Of all these parts, process time is the only segment that actually adds value. Unfortunately, $80 \%$ of the time a product is either spending time in queue or in movement. Thus there is a lot of room to reduce cost. But in a global supply chain context, the issues that inundate a firm, is where should it locate its plants in order to satisfy its customers with the least cost? A firm needs to take into consideration various factors that define its cost structure: location of raw materials, labor costs, demand projections, and coordination costs given geographic separation.

It is argued that the metric companies use to determine whether or not to expand their supply chains across international boundaries is "value density," which is defined as the revenue per cubic inch or per pound brought in by a product. Products like microprocessor chips, specialty chemicals and sports shoes are said to have a high value density and require the companies that make them to enter into complex supplier relationships that cross international borders. On the other hand, computing payments, taxes and exchange rates across borders can be "tedious, time-consuming, and expensive" for enterprises with supply chains that span the world. However, automation of those processes alone could reduce manufacturing costs significantly. For instance, for a company 
like Nike, streamlining the process of getting finished goods into the U.S. is an important factor. So is optimizing payments to overseas vendors.

Global supply-chain management can serve as a major tool to optimize costs in an integrated fashion along the entire manufacturing and delivery system worldwide. This is a significantly different approach compared with conventional cost cutting strategies implemented in their various compartmentalized departments such as transportation, manufacturing, etc. In today's globally competitive market, manufacturers should no longer look at different operational segments within one company as separate profit centers that need only maximize their own profit function. The competitive advantage in today's market derives from the integration of these different departments within one company to maximize the profit of the whole firm, which does not necessarily come about when each department maximizes its own performance. Today's businesses must devise a framework that integrates all functions of production and distribution if they are to become the lowest-cost manufacturer in their market.

The multiplicity of new companies in developing regions such as Asia and Latin America, as well as other regions, and the fact that entrenched multinationals are scrambling for and defending global-market shares, ensure that current cost-cutting imperatives will remain. Companies responding strategically with an integrated supplychain approach are meeting those imperatives and demonstrating dramatic cost savings. For example, Hoechst realized a $\$ 500$-million annual savings due to a re-engineered materials management initiative. DuPont achieved a \$1-billion price-cut due to re-engineered purchasing, and Rohm and Haas attained a \$75-million reduction in supply chain costs plus a $\$ 100$ million inventory reduction from a re-engineered supply chain. By some estimates, a petrochemical company can reduce total product cost by $20 \%$ to $25 \%$, plus cut product inventory by $20 \%$ to $30 \%$, using effective supply-chain management techniques. Considering the company's size, these efforts can bring about significant benefits.

\section{Adding Value}

There is a need to develop criteria to measure supply chain performance and value chain. In order to avoid local optimum and, instead, to focus on global optimization, the criteria needs to take into consideration the integrated performance of the entire supply chain and adding value chain in this process. Adding value is a widely used term that is attributed to firm strategies that result in increased profits. Adding value is a guiding principle often utilized in the various business units of a product-based firm: sourcing, manufacturing, and marketing. In a service-based firm the units that are the focus of value improvement are similar: sourcing, service-fulfillment, and marketing. In these various units, cost structures are improved by careful monitoring of suppliers, feedback from customers, and consideration for economies of scale and economies of scope. However, adding value is not a soloproject. Business units need to cooperate in making value-added decisions in order to make sure that channel-wide optimums are attained and not just local optima. This is especially important for firms that are distributed amongst many countries.

Also, since the global marketplace is evolving over time, business units need to optimize with agility in mind in order to overcome shocks that put the health of their businesses at risk. In the face of situations that increases lead times or costs, or decreases delivered quality or service, a firm must be able and willing to reallocate resources in order to stay competitive. Much effort has been placed on gaining efficiencies by specific supply chain automation functions, such as reducing inter-country duty costs for global firms importing products and supplies, and reducing international inventory. Metric companies use value density to determine whether or not to expand their supply chains across international boundaries. Value density is defined as the revenue per cubic inch or per pound brought in by a product. Products like microprocessor chips, specialty chemicals and sports shoes have a high value density and require the companies that make them to enter into complex supplier relationships that cross international borders. Varying tax and customs rules, multiple currencies and numerous transportation problems are among the challenges of linking a global supply chain. Information technology, particularly the internet, has played a key role in furthering the goals of supply chain. The most visible manifestation of the internet has been the emergence of electronic business web and its profound impact on business-to-business interaction in the area of supply chain integration. This new IT network is giving companies the far-reaching ability to create strategic as well as economic value added and generate wealth, or acquire "digital capital". The network has led to business 
web, a distinct network of suppliers, distributors, and customers who conduct business communications and transactions on the internet in a global market to produce value for end-customers and for one another. As a result, companies along the supply chain can increasingly do a better job in horizontal partnership for adding value to a product/service than vertically integrated firms. Thus, as the internet and digital economy expand, the notion of a separate, electronically negotiated deal with a network of companies, regardless of the country and geographical borders, at each step of value chain becomes a reasonable, often compelling proposition. However, at the same time economic and information technology factors in less developed countries are the challenges facing global business and supply chain management. Mexico, for example, is far behind the U.S. in Internet usage, and online marketplaces are almost nonexistent there. Even getting everyone in Mexico to agree on a collaborative process is difficult. According to the management experience at Coca-Cola de Mexico, a Mexico City-based subsidiary of The Coca-Cola Co. in Atlanta, people are not used to a networked environment. Culturally, it is quite a big challenge. Nevertheless, the beverage company plans to establish close connections with its supply-chain partners and is rolling out SAP AG's Advanced Planner and Optimizer suite of supply-chain applications as part of that effort

Another company facing these challenges is Hunt Corp., a Statesville, N.C.-based maker and distributor of office supplies and graphics products. Hunt uses faxes and telephone calls to process transactions with some of its suppliers in Asia; a process that said slows the movement of goods through the company's supply chain. If Hunt establishes business relationships with suppliers in Mexico or other Latin American countries, which it's considering, Hunt may install electronic data interchange terminals in their facilities to reduce the amount of manual processing, he added. While even in North America, there are some serious challenges in convincing partners that the way to go is e-business. However, It's even tougher in developing countries. That requires companies to invest money in simply trying to get their business partners to go along with the whole idea of business-to-business in their supply chain management.

\section{References}

1. Al-Mashari, M, and M. Zairi,(2000) "Supply-Chain Re-engineering Using Enterprise Resource Planning (ERP) Systems: An Analsys of a SAP R/3 Implementation Case, "International Journal of Physical Distribution and Logistics, 30(3-4), PP. 296-313.

2. $\quad$ Forrester, J. W., (1958) "Industrial Dynamics: A Major Breakthrough for Decision Makers," Harvard Business Review 36(4):37-66.

3. $\quad$ Forrester, J. W., (1961) Industrial Dynamics, MIT Press, Cambridge, MA.

4. Hoyt, D. (2000) "Lucent Technologies: Global Supply Chain Management, "Graduate School of Business, Stanford University, GS-01, January.

5. Lee, H. and J. Amaral, (2002) "Continous and Sustainable Improvement Through Supply Chain Performance Management, “Stanford Global Supply Chain Management Forum SGSCMF-W1, October.

6. Margretta, J. (1998), "The Power of Virtual Integration: An Interview with Dell Computer's Michael Dell, "Harvard Business Review (March/April).

7. Reddy, R, and S. Reddy, (2001) Supply Chains to virtual Integration, McGraw-Hill.

8. Simchi-Levi, D., P. Kaminsky, and E. Simchi-Levi, (2003) Designing and Managing the Supply Chain, second edition, McGraw-Hill. 